\title{
Transformative Leadership Journeys: Learning and Identity of University Leaders of Engaged Scholarship
}

\author{
Katy Campbell \\ University of Alberta \\ David Peacock \\ University of Albert
}

\begin{abstract}
University-community engagement (UCE) researchers have developed taxonomies, frameworks and practices for the field, but have not deeply considered issues of social, cultural, political, geographical and economic dimensions of theory and practice in institutions and their communities, including faculty, staff, and senior leadership. These dimensions may include institutional and personal history, such as religious affiliations; epistemology; forms of leadership; power structures; and social locations, among others. These cultural forms are reflected in institutional discourse, for example the narratives of engagement actors, and can be expressed in a variety of cultural artifacts including personal stories of praxis. Leading community engagement efforts is a transformative values-driven activity; we believe that transformative leadership is a process of continual, transformative learning, which is fundamentally a process of identity transformation. The narratives of six institutional leaders of community-engaged scholarship (CES) in higher education are examined for how their various scholarly and professional identities have developed through transformative learning processes), revealing themes of serendipity, moral coherence, values congruence, agentic change, moral courage, authenticity, relational practice and generativity that integrate these stories.
\end{abstract}

Keywords: transformative learning, transformative leadership, identity transformation, communityengaged scholarship, agentic practice, ethic of care, values congruence, narrative inquiry, moral courage, authentic leadership

\section{INTRODUCTION}

This article explores the narratives of six institutional leaders of community-engaged scholarship (CES) in higher education. It examines how their various scholarly and professional identities have developed through transformative learning processes (Mezirow, 2009) and the challenging identity work required to sustain their activism in the academy. Through the processes of promoting, creating, structuring and evaluating new opportunities for community engaged scholarship, including teaching, in institutions of higher learning, these scholars and professionals can be seen to innovate new roles and functions within the community engagement field, although not without uncertainty and struggle.

This paper has three goals: 1) to illuminate, using a narrative inquiry method, the ongoing identity work of scholars who have become leaders in community engaged scholarship and administration; 2) to surface 
the ongoing struggles of many involved in the institutionalization of community engagement and community engaged scholarship; and 3) to highlight common characteristics related to the successes these scholar/leaders have accomplished in their work in institutional leadership roles.

\section{COMMUNITY-ENGAGED SCHOLARSHIP AS A DISRUPTIVE CHALLENGE}

Community-engaged scholarship (CES) is a "disruptive challenge" to mainstream academic scholarship, and involves an "identity jolt" for those seeking to incorporate CES into their academic career (Barker, 2004; Bloomgarden \& O’Meara 2007; O’Meara, 2006; O'Meara \& Bloomgarden, 2010). Yet the institutionalization of CES, as involving administration beyond the work of individual faculty, has been resisted by some in the academy as an instance of a broader new public managerialism (Bradley et al., 2017), another site for the corporatization of campus, even if cloaked in public good discourses. Attempts to structure $\mathrm{CE}$ have thus often proved difficult, with the roles of community engagement actors remaining precarious and accruing low status within their institutions. Leading community engagement efforts beyond the scope of an individual's research profile requires a kind of transformative leadership (Ramaley, 2005), a values-driven activity requiring substantial vision and communicative capacities. We believe, and hope to show, that transformative leadership is a process of continual, transformative learning. Furthermore, transformative learning is fundamentally a process of identity transformation. In other words, learning to become a transformative leader in an institution of higher education requires profound identity work, that is itself transformational.

This paper shares narrative conversations from an ongoing multi-year study that explores sociocultural contexts for community engagement in several Western, English-speaking regions (English-speaking Canada, U.S., Australia, and UK), as revealed through the lived experiences of engagement actors, to better understand how university-community engagement is theorized, practiced and supported in different cultural settings.

These institutional leaders of CES hold academic positions and designated leadership roles, at the Vice or Associate-President, Dean, and Director levels. They are also, for the most part, recognized scholars within the field of community engagement. This purposive sample came from a broader study examining the socio-cultural dimensions to the institutionalization of community engagement, in which we interviewed over eighty individuals, academics, professionals, students, and community partners, across, to date, twenty-six U.S., Canada, Australia and U.K. publicly funded post-secondary institutions.

In the next sections we 1) discuss theoretical frameworks for exploring the identity transformations of institutional leaders; 2) outline the study methodology, 3) draw out the themes of learning, identity and leadership; and, 4) suggest implications for the institutionalization of university-community-engaged scholarship (CES).

\section{THEORETICAL FRAMEWORKS}

\section{Transformative Leadership}

As post-secondary institutions have grown in the complexity and scale of their operations, governments have sought greater evidence of the impacts of their investments in higher education. In response, and across the U.S., U.K., Australia and Canada at least, results-based management techniques, organizational change consultants and new public management practices have been utilized by senior management to drive institutional reform agendas more akin to private sector rationalization exercises than traditional academic, collegial governance (Benneworth \& Charles, 2013; Croucher \& Lacy, 2020; Slaughter \& Leslie, 1997). These practices have served to widen the divisions between administrative staff and academic staff, and made the leadership and institutional carriage of community engagement agendas - even though a core mission of the contemporary university - suspect to some within the academy (Ogunsanya and Govender, 2020). Recently community-engaged research may be politicized outside the academy who question its "liberal" concern with social justice. When leaders of community engagement within institutions are seen to be aligned with the weakening of academic culture, their work becomes more precarious, and the 
community engagement agenda itself more fragile. Leadership of community engagement walks this line between respecting academic knowledge production and promoting the socially responsive curricula and research meeting the pressing human, environmental and economic needs of host communities. Navigating this complex and ambiguous cultural and political landscape requires transformative leadership (Saltmarsh, Janke \& Clayton, 2015).

Transformative approaches to change are necessary when complex demands, such as institutionalizing CES, require a significant expansion of individual and institutional capacities and new ways of working together (Holland \& Ramaley, 2008). Institutional culture and structure create a context "influencing how people understand themselves, what they perceive, and what they value" (Sandmann, Thornton \& Jaeger, 2009 , p. 5). We are interested in how institutional realignments to CES affect the identities of engagement actors associated with the domain. We explore what brings designated leaders to a place where they could contribute to and influence this institutional culture.

Leadership is a social construction that is socially and culturally situated. Bernardo et al. (2014, p. 117) define the challenge of CES leadership as respecting the integrity of a community's diverse cultural identities while facilitating transformation. CES leadership involves unique challenges because of the multiplicity of knowledge communities within the university that reflect an "expert", knowledge-maker orientation. This orientation to knowledge often creates barriers with external communities who claim experiential knowledge.

Shields (2020) identifies principles of transformative leadership in educational contexts: a mandate for deep and equitable change; deconstructing and reconstructing knowledge about justice and inequity, including attention to the inequitable distribution of power; emphasis on both individual and collective good; focus on emancipation, democracy, equity and justice; emphasis on interdependence, interconnectedness, and global awareness; and balancing critique with promise. Thus, the basic principles of transformative leadership - deep, transforming engagement with all stakeholders and serious moral and ethical transformation - reflect dimensions of deep personal, group and organizational learning and change (c.f. Caldwell et al. 2014; Ramaley, 2005). We have used Shield's work $(2004,2010,2020)$ to help us interpret conversations with these institutional leaders.

\section{An Integrated Model of Transformative Leadership}

Caldwell et al. $(2012,2014,2021)$ have examined six leadership models - charismatic leadership, Level 5 leadership, covenantal leadership, servant leadership, principle-centred leadership, and transformative leadership - for their ethical dimensions. Most recently, they have reframed these models as elements of transformative leadership (Caldwell \& Anderson, 2021).

Transformative leadership is a "practical, values-based approach to building relationships" (Caldwell $\&$ Anderson, 2021, p. 1). and optimizing the long-term interests of stakeholders and society. Bernardo et al. (2014) define the challenge of CES leadership as respecting the integrity of a community's diverse cultural identities while facilitating transformation (p. 117); and define the challenge of CES leadership as respecting the moral duties owed by organizations to their stakeholders. In this understanding, transformative leaders are ethical stewards that commit people to action, convert followers into leaders, and potentially convert leaders into change agents, remove barriers that hinder the development of individuals and groups, and pursue virtuous outcomes that create added value. Further, transformative leaders personally rethink their old assumptions and require others to do so as well (p.176) - a transformative learning activity.

Personal relationships, authenticity, moral courage and values congruence are at the core of charismatic leadership (Hayibor, Agle, Sears, Sonnenfeld, \& Ward, 2011), which is future-oriented and inspirational, creating a "change in people's hearts and minds that empowers people to become passionately committed to a great ideal" (Caldwell \& others, 2012, p. 178), and models ethical conduct (Angawi, 2012). Level 5 leaders are characterized by personal humility and great resolve, and focus on removing barriers for others and providing resources that they need to succeed. Covenantal leadership focuses on creating new meaning through a learning culture in the organization (Caldwell \& others, 2012). "Disruptive innovations" occur in such organizations because covenantal leaders seek learning partnerships and provide opportunities for all 
to experiment and create, empowering others. Aligned with Carol Gilligan's model of moral development (1993), serving others over self is fundamental to the personal identity of the servant leader, while principlecentered leaders feel morally obligated to create a more productive and moral society while becoming better human beings.

The transformative leadership model is not the only model considered by researchers in higher education. For example, Bradley, et al. (2017) describe a model of shared, or distributed, leadership highlights respect for shared values, collegiality, participatory action, purpose, insight, and generosity (p. 99). Noting that leadership is a "group quality", Bolden et al. (2015) explain that distributed leadership is a way that the multifaceted roles within a university are connected. Balancing bureaucratic requirements, especially within an increasingly corporatized context, with the need to create a climate of encourages the self-leadership skills of colleagues, relates distributed leadership to transformative leadership.

Common to all leadership models, emotional intelligence is the ability to identify and manage one's own emotions, as well as the emotions of others (c.f. McCleskey, 2014). While research has been mixed, various studies have posited that transformative leadership is one outcome of emotional intelligence (c.f. Kouzes \& Posner, 2010; Malhotra \& Kansal, 2017). If the aim of CES leadership is to facilitate transformation (and social action), while at the same time respecting the integrity of cultural identities of the engagement actors, balancing creativity and control (Bernardo et al. 2014, p. 119) requires profound self-awareness.

\section{Transformative Learning and Identity Transformation \\ Identity}

Individuals and groups define themselves according to their central and distinctive characteristics, including the values and beliefs they advocate and the expectations that they hold (Albert \& Whetten, 1985). Poststructural theorists construe identity as multiple, fluid, and dynamic, situated, contextual, situationally adaptive and changing over time and in different sociocultural settings (c.f. Kurzwelly, 2019). Research on academic identity has occurred in three waves (Barrow et al., 2020, p. 2), including identity fragmentation due to conflicting values and institutional culture change; social construction with tensions between agency and structure; and academic identity as an ongoing, unfinished project. We see all of these conflicts in the stories we heard. For this interpretation we take a broadly post-structuralist understanding that allows for more robust identities, and is better able to meet the challenges of multiple, sometimes contemporaneous identities. Leaders' narratives express learning as an element of belonging to groups with social and professional connections, which bolster professional identity through leadership of a community of practice. In the narratives that follow, each individual is aware that their identity is fluid, reflecting values and goals of the institution, the group, and the self as they negotiate multiple positionalities and roles. We will see our leaders crisscross these identities as their narratives unfold.

\section{Transformative Learning Theory}

First described by Mezirow (2000, 2003, 2009), transformative learning theory holds that personal meaning is constructed from challenging personal experiences and interpreted through social interaction. Badara (2011) describes learning that occurs through reframing, that "involves critical reflection on others' assumptions, and subjective reframing entails critical self-reflection of one's own assumptions" (p 15). Reframing is triggered by a "disorienting dilemma" through a critical (re)assessment of assumptions, values and beliefs, leading to cognitive dissonance and a "perspectives transformation". Recognizing this mismatch or discontent involves exploring new roles, relationships, or actions resulting in skills

development, cognitive and behavioral rehearsals; and finally reintegration of new values, roles, relationships and actions into one's life on the new basis defined by one's transformed perspective, even though existing "habits of the mind" are very difficult to overcome. (Christie et al. 2015). Fundamentally, transformative learning is a project of identity development.

Mezirow (2006) distinguished between the notion of learning as addition, and learning as change, which requires a profound "re-think" of concepts, values and beliefs. In other words, learning as change catalyzes cognitive and emotional adjustments to what is known in an unencountered context, a process that creates 
some degree of anxiety and that ultimately leads to action. In view of this, learning involves disruption, disjuncture; dissonance, and may lead to changes in the self (identity) that occur through social interaction (Illeris, 2014, p. 25).

Inherent in learning, conflict arises at personal and other levels of identity and provides opportunities for learning and readjustment. Disorienting dilemmas may lead to identity jolts. Barrow et al. (2020) identify the changing culture of academe, including a tendency to interdisciplinary and transdisciplinary work, and precarity, as a destabilizer of academic identity. Horton et al. (2014) direct us to the traumabased literature, where individuals describe their personal struggles to deal with events that challenge a valued identity or that cause perceptions of this identity to be fundamentally revised, in other words, a perspectives transformation. The loss of a loved one, a relationship breakdown, or the loss of a job may trigger identity conflicts.

In summary, a transformative learning experience becomes part of an individual's self-narrative; involves feelings of agency, efficacy or empowerment; and is a moral imperative or call to social action (Badara, 2011). Through a social constructionist understanding of identity and learning, Mezirow's perspective transformations are necessarily relational, or forged in relation to the views of others, as well as the self. While they may reflect the "inside view" of these changes, they offer a useful starting point to understand new leadership activities in community engagement.

A narrative approach seeks to uncover these layers in order to reconstruct the understanding of identity formation and transformation. Next, we turn our attention to narrative as a method of inquiry, a social process, and a tool of creation for narrative self-identity.

\section{Research Design}

Narrative Inquiry

Stories create cultural archetypes, or personas, and power structures related to individual and group agency (Goodson \& Gill, 2011, p.103). Individual narratives of the experience of leadership in community engagement are likely to be "multiple, multivoiced, discontinuous, and fragmented" (Sermijn, Devlieger, \& Loots, 2008, p. 636). In other words, our identities shift as we make meaning of our decisions and learn from our experiences, telling and retelling our stories with new perspectives, and in different social settings, for different purposes, i.e. storying our identities.

We structured our participant interactions as a narrative inquiry, seeking to engage others in a social, fundamental project of identity formation and transformation, understanding the values, assumptions, relationships, events and contexts that make one, oneself (Goodson \& Gill, 2010). This approach required us to become immersed in the participant's story, asking probing questions to reveal more layers, sharing emotions the story evoked, telling matching stories; and meandering with the storyteller through the landscape of memory. Sometimes, this collaborative journey unfolded over several conversations and correspondences, continuing with the sharing of transcripts and the clarification or extension of insight.

Webster and Mertova (2007) found no single narrative inquiry method that predominates, but describe a critical event narrative approach, aligning well with the concepts of identity jolts and disorienting dilemmas. A critical event is defined as an unplanned and unstructured event that happens internally or externally, that causes one to critically reflect on one's perspectives. Mertova and Webster (2012) describe the significant impact a critical event may have on one's professional choices, explored in all of the narrative shared in this paper. During our narrative conversations, we explored life events such as divorce, loss of position, misogyny, financial stress, professional exclusion, failure, social and political activism; even religious conversion - many of which led to fundamental changes in personal and professional circumstances. These critical incidents, dilemmas or identity jolts may be experiences that the researcher shares, allowing her to add new layers to the meanings being made.

The process of narrative inquiry is not without challenges; ethical issues of voice (authenticity), representation, access, power and truth (interpretation) are involved. Leggo $(2008$, p. 8$)$ reminds us that we always enter into a "co-production" with the text and the author, bringing our own sociocultural views and experiences to the readings. The researcher must take care to interpret a narrative with relational ethics in mind; be reflexive and open to critique in the retelling of the story. Narrative researchers struggle with the 
integrity of the researcher/participant relationship; this concern is exacerbated if the study involves identifiable individuals by virtue of the context or discipline (Chase, 2005). Sometimes, disguising context and anonymizing accounts are not enough to meet this covenant. As the institutionalization of the scholarship of engagement has been formalized and well-documented by the Carnegie Elective Classification for Engaged Institutions framework, institutional leaders in the academic community are well-known. In this study, a collaborative narrative compact with engagement colleagues led to conflicts that required us to substantially reform several narratives in some cases. For example, as we share the transcribed conversations with participants, we sometimes encounter shock and surprise at 'unpolished' language, which happens often with academic participants. Negotiating the inclusion of the conversation "as is", to capture nuance and texture, is a process of tact and empathy and may not result in the authors' desired outcome. However, in such cases we actually learn more about narrative identity.

\section{Participants and Consent}

For this paper we selected the stories of six senior institutional leaders of CES, four women and two men, out of twenty-one leadership narratives. All the participants told compelling stories of the disorienting dilemmas and identity jolts they have experienced as senior scholar/leaders; these six reflect very well the themes that arose across the narratives. The six featured institutions, five in the United States, and one in Canada, ranged from small regional state universities to medium-sized land-grant universities (in the U.S.), and large, research-intensive universities in different geographical and sociocultural contexts - southern, mid-western, and northern North America. The American participants' universities are all members of the Carnegie elective classification for community engagement.

This small subset of individuals was purposively chosen from the wider study on the institutionalization of CES, in order to identify individuals with knowledge and experience of leadership of community engagement initiatives within their institutions (Denscombe, 2014). Through the Board, on which she served, Author 1 approached Engagement Scholarship Consortium (ESC) members with a proposal to become involved in the study. We also used personal and professional contacts outside of ESC members, and involvement in our own institution's Carnegie classification pilot. Before the COVID-19 pandemic stalled air travel and universities closed down in March, 2020, Author 1conducted five site visits, one in the UK, three in the US, and one, with Author 2, in Australia. For each site visit the primary contact identified additional likely participants, and facilitated contact through email so that the study outline, institutional ethics approval, letter of invitation and consent form could be shared. Collaborative conversations were conducted and recorded with participants, centered around the participants' early school years, journey to current work in community engagement leadership and activity, and how their understanding of their work has changed over time. In some cases, with consent ethnographic observations were made of classes, workshops, presentations and committee meetings, and institutional community engagement documents. We were invited to attend the mid-pilot convening of the Australian Carnegie pilot in February 2020, a group of nine universities sharing experiences and strategies in a two-day intensive workshop, during and after which we interviewed institutional representatives. After March, we continued the study via Zoom calls and email follow-ups.

\section{Data Analysis}

We applied a constructivist grounded theory approach (Charmaz, 2006) to the analysis of our interview data. Coding of transcripts proceeded in several stages and involved constant comparison, working separately and then verifying the coding together. We invited participants to engage reflexively with their transcripts as the study progressed; themes began to emerge. This kind of approach is compatible with narrative inquiry because issues of importance to participants emerge from the stories that they tell in conversation with the researcher; in the telling and interpretation knowledge is co-produced (Mills, et al., 2006). The authors come from different, although compatible, theoretical frameworks and positionalities; we have used different theoretical lens to understand the experiences of other engagement actors, for example, professionals. As a feminist scholar, Campbell also is sensitive to the identity narratives of the women who were interviewed. 


\section{THEMES OF LEARNING AND LEADING}

\section{Serendipity \\ Mary}

The way we tell our stories reflects the meanings we have begun to assign to our experiences, and the decisions that led us to those experiences. For example, several of the participants referred to luck, good fortune, serendipity or "magic" in tracing the pivotal actions leading to new relationships or opportunities scaffolded towards leadership. Mary, who founded a central CES unit on her state university campus, assigns her good luck to timing, "I would say to some extent it was early enough in the engaged scholarship field that I got to shape some of the language." However, her caliber of work was so visible that her vicechancellor of research at her institution invited her to become part of the Carnegie team, "which then morphed into my ability to open an office, and to create sort of a meaningful engaged research process." While she couldn't say "that any of it was intentional....it all seemed to fit". Mary's explanation is typical of many of the scholar/leaders who remember "drifting" into the field, although they understand in retrospect their core values led them there.

\section{Pitor}

The leaders represented in this paper did not share a common context, encounter, or career trajectory, but through a series of identity jolts, each developed what we have identified as moral coherence, an ethic of care, relational practice, moral courage, agentic practice, authenticity and generativity. Pitor, a leader from a large, Eastern land-grant university, describes this as animation, "A lot of folks that are involved in our movement are so animated by their very, very core, their identity is centrally shaped around social justice...that when they run into folks that aren't that way, it doesn't quite seem right to them. Pitor's description of social justice as the core identity of their colleagues is, for Shields (2004), a core driving force of a transformative leader. Under this construct, we see that as leaders encounter disorienting dilemmas, they purposefully seek a context of values congruence where they "come into their own" as transformative leaders.

Pitor believes that life happens "in a meandering way", although he understands that a narrative identity unfolds over time "as you have experiences and you make sense of them at the time. Then you do retroactive sense-making afterward because you realize the story you thought you were in had gotten different." He recounts a learning experience during which he realizes that "there were a lot of things that weren't gelling for me", realizing now how that encouraged him to support graduate students and colleagues in professional crisis. In his leadership role Pitor has been described by his staff as an "empowerer."

In his account we see that what might be felt at the time as serendipity, chance, magic, or luck precipitated, or was precipitated by a critical incident leading to a disorienting dilemma. At the same time, these leaders were emotionally courageous, and prepared to take an opportunity that supported their values.

Mary

The excerpts above reveal elements of disruption leading to a narrative of change. For example, while Mary speaks of good timing early in her journey, she intentionally undertook graduate work in a different culture and returned home convinced that institutionalizing CES requires "political mapping":

I felt more supported (in Canada), because I thought that the historical and cultural context in many ways was more supportive of engagement principles... So that was really critical to me, politically speaking, for doing the work I was doing at the university, particularly with people with multiple disabilities.

Mary contrasted the polarized political context in her country with a different context, one that shaped her sense of social responsibility. Now, Mary wonders how resistance to the COVID-19 restrictions will influence "how engaged scholarship fits into the world and the questions we can answer." She understands that one's values must be congruent with the sociopolitical climate for learning and action to be successful. 
As these scholars engage in their transformative learning journeys toward leadership, they make decisions to move from one institution to another. While they may describe these decisions as responses to chance, they are intentional in that each individual seeks an environment in which their values, and their emerging identities as leaders, align with the values of existing leaders in their new professional homes. In other words, they need moral coherence in order to keep learning and becoming.

\section{Moral Coherence and Values Congruence}

Transformative leadership as activist leadership begins by identifying inappropriate uses of power that have created or perpetuated inequity and injustice (Shields, 2010). Coherence can be understood as internal consistency, in which "beliefs, feelings, goals and actions all influence one another, and are adjusted iteratively toward a point of...maximal coherence" (Ditto \& Liu, 2016, p. 105). Moral coherence includes reasoning and judgment about not only what is right and good personally and professionally, but also the accommodation of seemingly conflictual information that creates disruptions, or identity jolts. Seeking coherence involves finding or creating a mental or physical space where such conflicts are resolved.

Values congruence suggests fit, for example, the alignment or sharing of cultural values between organizations and their staff. A leader with moral coherence deconstructs structures of power, and emphasizes both individual achievement and the public good; their organizational home will either have to support their values or be open to significant change. The stories shared in this section reflect the identity work of moral coherence and the possibilities of values congruence.

\section{Lorna}

Lorna has held many leadership positions in the CES world. Her story traces a childhood legacy of community service, encouraged by her parents and youth organizations. She was recruited to higher education into several roles where the credit for quality community engagement and scholarship work failed to be supported by colleagues or supervisors; this problematic shaped her leadership journey. She worked within the university culture to advance community engagement scholarship in each institution; every time she decided to move on, from the Northeast to the Mid-East to the South, she applied to an institution in which she would experience greater values congruence. Throughout our conversation Lorna insisted that alliances that were disciplinary-based were central to a cultural shift with department chairs and tenure and promotion and tenure (P\&T) committees. She planned both formal and informal learning events with academic leaders to surface understandings of CES throughout the disciplinary cultures:

Any of us that worked with a department head, talked about engagement... over time people began to look at what are we doing when we actually evaluate someone for P\&T... they had engagement, but they didn't call it engagement.

She notes the importance of "changing the language and pointing to what this category meant." Her team developed a position paper with recommendations, most of which were accepted as part of the university's T\&P guidelines.

In our conversation Lorna comes back many times to the idea of democratic values; these have framed her leadership praxis. Applying for her most recent position, a meld of extension, engagement and economic development, the President asked her to come up with "three big ideas". She had been interested in applying to the university because it had already invested in CES and would potentially support her desire, "to do something to further the institutionalization of engagement, so that people could get credit for their scholarship of community engagement no matter what title they wore.

She "wanted to make sure that democracy and democratic practices, which is really the fairness, the mutually beneficial part of engagement...was a major thread throughout the university and all fields." She developed an institute that, "Helped people figure a way to integrate democracy and the practice of democracy, not only in their leadership, but in their teaching and their way of participating with community partners." She defines democracy as "every voice (having) an equal weight... if there are issues, you create 
groups that allow people to have a voice, a respected voice... and to come up with solutions, I wanted people to have an equal ability to practice these."

Possessed of covenantal, servant, and principle-centered leadership characteristics, Lorna exemplifies democracy as equity, diversity, and inclusion. She tells a story in which she modelled inclusive behavior that influenced the outcome of a Presidential initiative:

I would say, 'As a university team we demonstrated mutually beneficial listening and learning by creating a team... who worked as equals to identify major issues higher education should address... (resulting) in a state report that was valued, and it demonstrated to others a method of collaborative learning and reporting. We noticed afterward that key leaders around us started doing the same thing.

In one case the President wanted to pull together a group from the private sector with agricultural leaders, to meet with key individuals within the university, but did not include community members. Lorna moderated the session.

We didn't have racial equity at all...I suggested that we invite...some of the people that are learners, and some of our volunteers and others to the group....I would call on the President to answer, and then I gave each person present time to answer the same question. This way each attendee could listen to other members of the group. The President was so fascinated by this that he stayed an extra hour just to hear the voices of the people there... To me, that was a way to model democratic strategies, because everyone had a voice...I tried to model...democracy....as a practice.

As a transformative leader, Lorna opened space for both individual achievement, and consideration for the role of the university to model the best possible practices of social justice for the public good, which she frames as "democratic", a term used by American participants but not Canadian, Australian, or UK leaders. She shows moral courage by helping to create organizational change; she is unable to belong to an organization with which her values are incongruent. She has experienced gender inequity personally, has left institutions because of it, and supports and mentors colleagues and students who challenge their status. Wherever she was, she trained female leaders of departments and counseled female faculty, for example, negotiating salaries.

\section{Samira}

Lorna exemplifies emotional and spiritual intelligence in her approach to relational practice. Similarly, Samira, a leader of CES initiatives in a Canadian university, has had many roles in both the private and public sectors, through which experiences she scaffolded on the moral codes developed growing up in an entrepreneurial, service-oriented family. While she has worked in a number of different settings, she is driven by "liberal social values" that she traces to her family's ethic of community service and, especially, to one disorienting dilemma. Her sister had been born with a severe health condition; to save her life her parents were compelled to pay out of pocket at the Mayo Clinic in Rochester, New York. Samira, "understood what it was like to grow up from her perspective, different and challenged by health." As a result, she expresses a global concern for those without access to universal healthcare, working for some time in related social organizations.

Samira explicitly relates her experiences to her identity as a Canadian and a learner, reflecting on her quest for values congruence. For example, she worked as a graduate student intern with USA Today on the editorial board during the 1992 presidential election, and returned home with "a strong commitment to working within the public sector". She learned, by travelling, "that I'm really aligned with the Canadian identity."

Samira is quite clear that her self-identity includes her integrated personal and professional identities, suggesting that she was conscious of, and intentional about, achieving moral coherence, 
What often is personal becomes professional and what often is professional becomes personal...And I'd say in the last year or two there was some disorientation because of that... It's hard to navigate...I'd say (with) my experience navigating sometimes really difficult, personal, professional, familial, marital challenges, which are often repeating patterns...one journey leads to another, and with my own maturity and my own value system continuing to grow, I recognized that I was repeating these patterns.

Samira scaffolds her learning, often finding, "If you enter that doorway, it can lead to a greater opportunity and transformation...I think if I look back on my own journey in life...I've been able to explore and then bring on greater opportunity and transformation for myself and hopefully for others." Her story reflects the generativity of multiple, intermingled identities, "I think a lot of those experiences helped build some values within me that I have continued to express, or learn about, or commit to in my adult life, and even how I raise my kids".

She relates her personal values to her leadership values, learning to take a larger perspective, defining community as interdependence, "Our role in Canada and our opportunity to help those in Canada, but also beyond, is really important to me...Collaborative leadership... is the way I have always tried to function". Leading engagement initiatives in her institution, Samira reveals that "unlearning" requires greater cognitive effort than learning something new. She has experienced a perspectives transformation about community engagement and intercultural differences in its praxis, a process she again relates to a Canadian identity journey, "I think a lot of my colleagues across Canada see that issues are different in Canada and that's okay....I've been on my own personal and professional journey to learn and unlearn knowledge gained or bias developed over the years", in particular, knowledge related to colonization, and "Indigenous...ways of knowing, doing, connecting and being....I've been really fortunate to work on the Indigenous strategy (here).... and to think back to the way I was brought up.

Like many engaged scholars, she has confronted her privilege and is agentic about dismantling institutional power structures.

I've had to unlearn a lot about our institutional traditions... because of (its power and resources and strength )...we really do need to be more thoughtful and...willing to learn more from our partners' perspectives...it's challenged a lot of my beliefs.... I have learned...to do it in a truly authentic and good way to achieve some mutually beneficial or shared outcomes.

Samira is critical about her learning, both formal and informal, a necessary element of perspectives transformation:

When I think about my whole journey through life, I'm really lucky that I've been in this continual journey of evolution and learning.... I always had new exciting projects to lead... new partnerships to explore... new team members join the team... from the very beginning, I was learning every day and learning in a different way.

Lorna and Samira each tell a story of identity jolts and disorienting dilemmas, leading to perspectives transformation that relates to social justice and the role of the institution for the public good. Each has moved, to different sectors and different institutions, to find values congruence. As the transformative leadership literature tells us, echoed by the transformative learning literature, these processes of profound change tend to lead to a deeper personal sense of authenticity manifested in relational, ethical practice.

\section{Authenticity and Relational Practice}

Transformative leadership occurs in relationships; "authenticity is...the ever-evolving process of discovery rooted in the self but existent within the confines of relationships amid congruent values" (Bishop, 2013, p. 6). May et al. (2003) define authenticity as consistent transparency, exhibiting high moral 
capacity and critically reflexive practice. Sparrowe (2005) likewise relates authenticity to the moral compass of a transformative leader, while Bhindi and Duigan (1997) find authenticity primarily in social interaction, or meaningful relationships that support core, significant values, intentionality, and spirituality, referring to a celebration of the shared meaning and purpose of relationship (p. 119). Eagly (2005) criticizes the literature on authentic leadership for the emphasis on the leader "to the exclusion of their relationships with their communities, and the fault lines that exist between people who differ in gender, social class, education, and ethnicity" (p. 406) and, therefore, access to power.

In our view, authenticity requires relational practice from a place of moral coherence. Larson and Murtadha (2002) relate leadership for social justice to an ethic of care (c.f. Gilligan, 2011) as the fundamental starting point to "reframe and reorganize (organizations) away from hierarchical and rolebased images of leadership" (p.141); to model, and persuade organizational actors to understand that their work is to enter relationships with others rather than to assume bureaucratic administrative roles. Furthermore, framing educational institutions as possible sites for social justice, reimagining an ethics of leadership argues for moral and spiritual language such as compassion, forgiveness, and humility.

Characteristic of these leaders, emotional intelligence is exemplified by empathy, awareness, selfregulation, social skill, and motivation (Goleman,1995; Malhotra \& Kansal, 2017). An emotionally and spiritually intelligent leader is often viewed as an authentic leader. So, rather than being true only to oneself, the authentic leaders in this study are unfailingly true to others. The following narratives reveal the transformative identity journeys of two of these leaders whose innate characteristics of empathy and compassion are tested by critical incidents, whose outcomes are reconciliation and values congruence.

\section{Antoine}

Antoine grew up in a working-class family, inculcated with the values of integrity and reciprocity. He was the first to attend university, "A lot of people have helped me in my life...I gravitated toward anything that allowed me to help people improve their quality of life.... I was in a lot of mentoring programs with children". In one of his jobs he dealt with many vendors, who:

Want you to buy their product, but they want to do something to support your efforts. You start to learn how to channel those things in ways that help other folks. That's kind of how I've always been. The opportunity that I've had at this university have all been because of that.

Antoine's identity work references his childhood circumstances, and involves entrepreneurial thinking that was directed at the public good. "If you can figure out the essence of who you are and what your passions are, and you continue to work, you'll start to get led toward where you should be". In his early career he took a support staff position, went on to corporate and foundation relations fundraising and, finally, to the President's office in an academic role.

You're in a situation where your station in life...if it's not the best of circumstances, with resources and opportunities and those types of things...you're doing all that you can. The only way that changes is ...if there are people who see potential in you and are willing to help you develop because they know you're going to help someone else.

In his position Antoine was an observer to a state funding scandal that catalyzed his transformation into a leader of CES. As a result of the trouble the university was provided a significant disbursement. The President asked him to strategize how to use the funds to increase engagement for the university community. Newly introduced to CES and learning about the Carnegie elective classification he proposed to use the framework as a foundation for the structure he hoped to build. He knew the institutional culture was initially to "reject anything new", so his approach was to define this concept through the work...If you could paint a picture of what the work looks like and the benefits, and not try to convert them...just create space for those faculty members who were interested, you could start to get some traction. 
He realized, "Once you start to say, 'I'm an engaged scholar versus a scholar', then you have to define what's different between those." He avoided that argument because it pitted, "The traditional scholarship or 'real' scholarship," against engagement scholarship.

We try to focus mainly on the scholarship....and the component that was consistent... was the involvement of a community partner... All of the projects that we recognize in our awards program included those tenets.... We really didn't have to keep saying it because what I found (is) you're actually creating pushback.... as opposed to just doing the work and pointing to the benefits of that work.

Like Lorna, Antoine is well aware that tenure and promotion are the "coin of the realm" in academe. He also knew the professoriate, who he needed to bring into the project as engagement actors, would have to be strong scholars in their research, teaching, and commitment to community engaged scholarship". Early in the development of the CES culture on campus, he attended annual meetings of the National Outreach Scholarship Consortium (later, ESC) to learn about how to institutionalize CES through respect for institutional culture. He modeled relational practice in his decision to create a center, "For communitybased partnership...(involving) faculty members who I had worked with over those first two years of this office." Realizing that the engagement work was too closely identified with its early adopters, he thought, "We've got to create a space and a platform for ideas to come together...25 faculty members...started (a) council....a big part of the work that we do now...it's our anchor." The council has grown to over 150 people and is more inclusive, involving students, community partners, and a growing cadre of faculty members. Meeting twice a semester, it sponsors an awards program, community engagement funding and graduate student support. As a member of the culture of meritocracy he strategically created a more competitive system to distribute the research funds:

It gave us an opportunity to get more folks under the umbrella...finding out if other faculty members were interested and could collaborate. This was a new frontier for them.... For faculty members to successfully engage in this work here you have to have...teaching, research and service, and publications and external funding.

His office added a grant-writer to its services, establishing alliances with reluctant Deans by sharing the resource with interested faculties. But, despite having secured ongoing support from the President's Office, Antoine knew that directly funding a select few research projects, in the long run, "Wasn't a good thing... because we knew in order for them to...be able to put that in their T\&P dossier it needs to come from someone other than us". The initiative succeeded in attracting over $\$ 100$ million in grants. He is proud that, "in our work, the first thing people think about is the impact on communities because that's what I drill. 'What's the relevance of our work'...What's the difference we're making?"' Like other leaders, he embarked on a program of education:

You have to really do a lot of heavy lifting. You have to think through who needs to be allies and why. You really have to talk about what's going to be... different as a result of whatever you're trying to propose. How do you articulate being able to assess the difference? If you're not able to do that consistently, you're not going to be successful.

The Dean of Engineering was initially a resister. This Dean was approached by students who wanted to start a chapter of Engineers Without Borders. "At the time, their dean wasn't really interested in supporting that...I wouldn't do anything to drive anything between our relationship. I called him." The Dean agreed to not block the request if Antoine agreed:

To pay the charter and get it started...That work...was just incredible...Every semester...that group received some type of recognition. The Dean was standing there in 
the photo smiling...So he just builds on this piece...I knew we would have to have people like that for us to have a chance.

Asked to describe a milestone of his agency, Antoine recounts a painful process of establishing a refereed CES journal with community perspectives. He was initially surprised at "a lot of pushback from that". He learned from his council to "have as editorial board some of the top scholars who happen to do work in communities... (and) we were able to convince our (initially reluctant) president and provost at the time to give it a chance." Antoine knew that the journal piece was important to "what we were building here. Then (the next important piece) was going to be joining ESC, because again it gave us something to celebrate in terms of recognition of our work... We were going to be the very first non-land grant institution that they accepted".

Antoine's emotional intelligence opened him to learning experiences in his early and mid-career, leading to a leadership role that transformed the culture in his large, southern US comprehensive research university. Learning from leaders in a national consortium, and skilfully adapting their experiences and advice to his own context, Antoine's empathy for others encouraged a culture shift in several different disciplines and ensures that the "dignity" of community engagement underlines an approach to scholarship for the public good. In his carefully planned change strategy, one of commitment to the success of others, Antoine exemplifies qualities of Level 5 and servant leadership.

For Antoine, who began his leadership career almost haphazardly, achieving a Ph.D. in a discipline far from his initial choice of science, identity jolts through early and mid-career resolved into the collaborative, relational and strategic leader who built a CES culture on a traditional campus. He created an intentional self-learning program by seeking out knowledgeable and experienced peers in the sector, adapting strategies they advised, and reflecting on and adjusting their implementation. This reflects moral courage, which manifests in institutional and community agentic practice. The following story highlight this characteristic of the transformative leader as moral actor.

\section{Moral Courage and Agentic Practice}

We saw earlier that authenticity in leadership is based on emotional and spiritual intelligence, integrity, relational practice, and explicit embodiment of ethical and moral values. Action implies moral agency as leaders distinguish between what is right and worthwhile. Bogue (1994) describes this leadership style as a "venture in moral philosophy" with attributes of "honour, dignity, curiosity, candor, compassion (and) courage" (p. 13). Further, Burns (1978) relates authenticity to a transformational experience, resulting in transformative action. The transformative leader is concerned with the moral, end goals of justice and equality (Shields, 2010). While using different language, Pitor, Mary, Lorna, Samira, and Antoine all explicitly identify these goals in their narratives. From a post-structuralist perspective, identity is intersubjective, shaped by the actions and reactions of others; individuals are active in this process, aligning their identities with a group with congruent values (Warhurst, 2012).

\section{Catherine}

Catherine's raison d'etre has always been, "The institutionalization of what is now called community engagement. But I was involved with some phase of...community engagement my whole life because...my personal mission was "knowledge in service to society"'.

Her narrative traces a journey from a suburban childhood to an Extension community-based educator to a university leader, working across the American midwest to a southern university with a different culture, skeptical of "outsiders". She describes becoming interested in community outreach as a summer research assistant in a rural community, where she had several "transformational" experiences that she considered a "turning point to commit to that kind of work". Community-based mentors taught her "so much about what it was like to do front line, community-based education, and in low socioeconomic groups", that when she graduated with an undergraduate degree in life sciences, she chose to go to "another very rural community...very low income, (with) a Native American reservation...very eye opening to be working and trying to make a difference in this kind of environment". The theoretical components of her 
degree, "this ecological perspective of psychology, sociology, economics...all put together," she found resonant and "foundational". The team she was with developed community educational programs, including teacher-leader training. This was Catherine's first encounter with Indigenous cultural resistance to "the patriarchy... I couldn't get the Native American women on the reservation to come to educational programs unless their husbands came with them... suspicion of education, suspicion of knowledge; suspicion of people from outside".

As a district director, she annually represented the university to the County in salary and budget negotiations for their local cooperative extension agents and office. While seeking equity for female county workers she encountered a conflict of social values; overt gender discrimination in the county boards who, "Were largely well-intended, but good old boys." In this culture she was

Trying to negotiate not only for the agriculturalists who had not had a female district director, a supervisor who was female and not an agriculture person...(and) what I have scars about... is being a woman in administration or in higher education as a leader. First of all, in a field that's male dominated...so coming from youth development and the home economics, the women-dominated fields, they pat you on the head.

Catherine encountered the fault lines referred to by Eagly (2005), an urban professional woman from a university in a rural community where the majority of her community were "traditional" males. "And they would say, "Well, why would this extension home economist need to be paid more than the secretaries in that courthouse where they were housed?"' In a common thread running through the stories, these leaders must learn to pivot, finding themselves agents of change, acting as interpreters, educating colleagues and partners about structures of power and inequity.

Catherine achieved a doctorate in adult education and the theory and practice of administration, "One of my comprehensive exam questions was to speak to the philosophical differences between adult education, and its social justice orientation, and business administration." She recalls the process as an act of disruption, "I was fortunate. I had a wonderful woman from the prestigious business management department who served on my Ph.D. committee...she was an outlier in her all-male department as well“", that resonated with her own feelings of being "like an outlier too--in a university having been this scholarly practitioner, the practitioner." Now a director of university extension, working closely with communities, Catherine felt it was important to teach, resulting in cognitive dissonance.

I was affiliated with land-grant universities where there was a value placed on that service component, but it was undervalued overall, as... is (adult education) be it formal or nonformal education....I continued to try to... be the scholar while being a practitioner and administrator....We started to think about outreach as scholarship...I moved from...doing the work, to leading the work, to studying the work...I was able to integrate these functions more or less.

Catherine's vision honored, "These university county-based family and youth agents (who) were family experts....They could bring all this knowledge from the university.... this is where university knowledge can partner with indigenous knowledge... it's a very sophisticated community-based education and research platform".

Identity work required that she carry, "a piece of all these different contexts and opportunities....I was always a scholar practitioner...scholarship can be reflective practice....I always admired people who were scholarly administrators, and so I took on that role as well". Although Catherine had a Ph.D., she was well aware of the "duality" of being an extension academic and the challenge of integration:

So I've always had a faculty position. And you went through ranks from instructor, assistant, associate, to full in the department of extension. But of course the academic side 
never really thought that extension's faculty were of the same standard as tenure and tenuretrack faculty, but rather citizens of a second-class classification.

Catherine's praxis reflects values congruence, an opportunity to do work encouraged by her value system. When she moved to this university her role enlarged to Associate Vice-President of the public and outreach functions, and a director of a center for continuing education. Upon arriving she discovered that she was the first woman to lead the 600 employees. She had learned that high performance in an administrative position did not mediate against its precarity, so she negotiated a tenure-track appointment. Key to her success "navigat(ing) institutional and field transformation", was bringing a scholarly lens to the work. Catherine acknowledges that the culture in her new, traditional southern university was very different from that of the Midwest; she faced cultural dissonance and "outsider skepticism" and, fairly soon, a critical incident.

I was charged with creating institutional and program change (but) the organization resisted. I moved swiftly to a highly inclusive strategic planning process... I had good evaluations from the vice president, but then he abruptly became risk adverse...I felt sabotaged and dismissed...After about a year and a half, the vice president...said they wanted to go a little different direction. Being a high achiever who had always had escalating levels of responsibility...this was quite a jolt.

This identity jolt

Was such a gift... at that point in my career I could then solidify and mix past roles and initiatives together, plus add the role of dissertation advisor, mentor of others, and be involved in developing emerging engaged faculty. There was this scholar-practitioner community-based education and research niche in my academic department I could fill and develop...(as a tenured academic) I was able to bring these pieces together, to help not only the discipline but the field.

Building capacity in an intentional way, she founded a well-regarded refereed journal in CES, became a frequent author of articles and books, consulted with universities around the globe and co-founded a national review board. While she experienced a disorienting dilemma as transformative learning, Catherine realizes in retrospect that she made a significant and enduring contribution to culture change at this university, but also internationally in the growth of CES. Her name is respectfully invoked by many of these leaders during our conversations, suggesting that Catherine has the generative attributes of a covenantal leader.

\section{Generativity}

Mary

Finally, Mary exemplifies the active creative change agency of transformative leadership. With her team, she created both a student and a faculty academy for the campus community and, although retired, continues to actively support learning activities in each. Knowing that the "third leg" was missing, Mary's center sponsored a community academy, "Where we brought community leaders in who wanted to learn how to do that kind of research....(and) it's morphed into an addition of a public service fellows for students". Students are identified as scholars who work within communities for a term. Politically astute, she understood that her institutional culture would not support the notion of community service learning; but rather would be interested in students "learning to be engaged researchers and work with communities." From her own experience she knew that "one of the challenges that we had to address was the belief that an engaged scholar couldn't get published, and therefore wouldn't get tenure and promotion", a frustration identified by writers like O'Meara (2006), and shared by many of the leaders who are (re)framing engaged scholarship as legitimate research. Academy members go through an interview process and attend a series 
of workshops over two semesters taught by engaged scholars and their community partners. In the second semester, "meetings focus on things like ethics and challenges and funding. Then that summer they implement the project and evaluate it through the next year." Mary talked about the power of this approach:

Those faculty who understood what it's like to do a research design with a community member, wrote good research designs, did good research... could take that back to their dean...(the success was) institution-wide, and that's the power that came out of those workshops where scholars from all over the university would talk about what they were doing, would discover there were ways that they could help each other or add research power to somebody else's research idea.

An off-campus four-day retreat was later added to help these engaged researchers move the scholarship to the "next level", where they problematize the tenure and promotion process. During this process they address questions like, "What are the challenges that you've faced with your communities and how did you address them? How are students being incorporated into the research piece? But how is that helping them grow as a future professional in their field?"”

\section{DISCUSSION}

\section{Supporting Transformative Leaders of CES}

These accounts of praxis reflect the power of informal learning in leadership development, and propose the related identity transformation as a critical, creative process rather than as an end product of learning. Identity work, thus, takes place in a context of "contradiction, disruption and confusion", the context of transformative learning, "requiring intentionality, consciousness, or what is more specifically referred to as reflexivity" (Carroll and Levy, 2010, p. 215). This work is primarily relational work, a moral activity or the "ethics of the interpersonal" (Cunliffe, 2009, p. 97).

The narrative self is not constant through time, "but the subject that experiences change, reversal, and surprise" (Sparrowe, 2005, p. 426). We have characterized these surprises as transformative learning, the resolution of them, as perspectives transformation. In these narratives the sense of self as a leader is disclosed through revelations about actions and interventions, as when Catherine and Lorna displayed moral courage by addressing gender and racial inequities; in the agentic practice of Mary, Antoine, Lorna and Pitor; through leading learning and listening initiatives; the relational practice and ethic of care of Antoine, focused on the success of others undertaking risky challenges; the intentionality of Samira. These leaders have a strong sense of moral coherence and have sought a place to practice their leadership that is congruent with their values, in some cases after serious disruption. Stories of identity jolts, critical incidents and disorienting dilemmas reflect the sensemaking essential to identity transformation, and while the narratives may flow, the self is revealed not by continuity but by "discordant concordance" (Ricoeur, 1992, in Sparrowe, 2005, p 426).

While transformative leaders continue to learn, they also lead other learners in transformative practices, through formal strategies, such as developing academic and professional journals, leading institutes and workshops, mentoring and coaching, making resources available to develop grantsmanship and P\&T dossiers, empowering colleagues to resist, and advising senior administrators. However, most university leaders tend to learn experientially, after they have been appointed (Bradley et al., 2017), As the field matures and the impacts of CES mitigate ideological, disciplinary and geopolitical divides we should be able to develop, support and evaluate a more robust culture of leadership development. In the past decade we have begun to see evidence of evaluation and the availability of resources to support exemplary CES in various disciplines, or, institutionally (c.f. Driscoll, 2014; Hart \& Northmore, 2010; Goodman et al., 2020; Morrison, 2020; Singh, 2017), but little on explicitly evaluating good CES leadership practices. One might extrapolate from the institutional evaluation literature, or return to researchers like Shields (2020) to compare leaders' performance to her eight principles for transformative leaders, but the field is ripe for a more empirical approach. 


\section{Can Transformative Leadership Be Taught?}

Is transformative leadership a skill that can be taught? University leadership programs for senior administrators exist, such as the Harvard Institutes for Higher Education and HERS Higher Education Leadership Programs for Women. The Rutgers Leadership Academy is an exemplar that is designed around evidence-based concepts related to transformative leadership (Rueben et al., 2018, pp. 245-248); the Academy employs pedagogical approaches that strengthen this process.

Finally, since transformative leadership is a relational, agentic practice, leaders may benefit from membership in transformative communities of practice. We present a few, below.

\section{Communities of Practice}

The Engagement Scholarship Consortium sponsors an annual Engagement Academy for University Leaders. Using case studies and other analytic tools, the Academy includes "the latest in best practices and literatures on the subject of leadership in community engagement, as well as the skills needed to implement changes". Author 1 is a graduate of an earlier version, a week-long institute for university leaders developed at Virginia Tech University.

The Academy of Community Engagement Scholarship (ACES) is a relatively "young" honor society of "leading community engagement scholars and practitioners and their most knowledgeable, collaborative and effective community counterparts" (http:/www.academyofces.org), that nominates members from international settings. ACES provides a forum for CES leaders and involves members in collaborative projects, for example developing a podcast highlighting exemplary CES activities, whose intent is to inform local, national and international policy agendas.

In the UK, the National Coordinating Centre for Public Engagement (NCCPE) provides consulting, tools, training and support to make "a vital, strategic and valued contribution to 21 st-century society through its public engagement activity" (https://www.publicengagement.ac.uk). For example, the NCCPE offers Engagement Leadership workshops and follow-up mentorship. The Oxford Women's Leadership Program supports emerging and current women leaders.

\section{Identifying and Promoting Leaders in CES}

Leaders in CES comes from many disciplines and backgrounds, some of which are aligned with engagement scholarship, e.g. extension practice, while others seem less related, e.g. example, mathematics. Paths to leadership varied from promotion within the institution to recruitment for specific positions. Generally, promotion within an institution is based on excellence in three categories (research, teaching and service); in reality, research productivity trumps the other two. Bradley et al. (2017) point out that whether research reputation is a proxy for leadership skills is unexplored, despite the fact that academic leadership requires a broad array of skills and knowledge. During an academic's career trajectory CES leadership seems to be discussed mostly in relation to service. Few universities studied by these authors attempted to define leadership in more inclusive terms than technical skills (p. 102), although transformative leadership skills appear to be more suitable for the academic context. The question becomes whether these skills can be developed. Taking a narrative identity perspective suggests that while some components may be innate (e.g. ethic of care) other transformative leadership skills may be nurtured through mentorship and critically reflexive learning and practice. 


\section{REFERENCES}

Academy of Community Engagement Scholarship. (n.d). Retrieved from https://academyofces.org

Albert, S., \& Whetten, D.A. (1985). Organizational identity. Research in Organizational Behavior, 7, 236 $-296$.

Angawi, G.T. (2012). Neo-charismatic leadership: A new theory for effective leadership in higher education. Educate , 12(2), 34-47.

Ashforth, B.E., Harrison, S.H., \& Corley, K.G. (2008). Identification in organizations: An examination of four fundamental questions. Journal of Management, 34, 325.

Badara, I.A. (2011). Using transformative learning theory to investigate ways to enrich university teaching: Focus on the implementation of student-centered teaching in large introductory science courses. [Unpublished doctoral dissertation]. University of Tennessee. Retrieved from https://race.tennessee.edu/utk_graddiss/945

Barker, D. (2004). The Scholarship of Engagement: A taxonomy of five emerging practices. Journal of Higher Education Outreach and Engagement, 9(2), 123-137.

Barrow, M., Grant, G., \& Xu, L. (2020). Academic identities research: Mapping the field's theoretical frameworks. Higher Education Research \& Development. http://10.1080/07294360.2020.1849036

Benneworth, P., \& Charles, D. (2013). University-community engagement in the wider policy environment. In P. Benneworth (Ed.), University engagement with socially excluded communities (pp. 223-241). Dordrecht: Springer Netherlands. doi:10.1007/978-94-007-4875-0_12

Bernardo, M.A.C., Butcher, J., \& Howard, P. (2014). The leadership of engagement between university and community: Conceptualizing leadership in community engagement in higher education. International Journal of Leadership in Education, 17(1), 103-12. http://10.1080/13603124.2012.761354

Bhindi, N., \& Duigan, P. (1997). Authenticity in leadership: An emerging perspective. Journal of Educational Administration, 35(3), 195-209.

Bishop, W.H. (2013). Defining the authenticity in authentic leadership. The Journal of Values-Based Leadership, 6(1), Article 7, 1-7. Retrieved from https://scholar.valpo.edu/jvbl/vol6/iss1/7

Bloomgarden, A.H., \& O'Meara, K.A. (2007). Faculty role integration and community engagement: Harmony or cacophony? Michigan Journal of Community Service Learning, 13(2), 5-18.

Bolden, R., Jones, S., Davis, H., \& Gentle, P. (2015). Developing and sustaining shared leadership in higher education. London: Leadership Foundation for Higher Education.

Bogue, E.G. (1994). Leadership by design. San Francisco: Jossey Bass.

Bradley, A.P., Price, T., \& Paulsen, N. (2017). Promoting leadership in Australian universities. Australian Universities' Review, 59(1), 97-105.

Burns, M. (1978). Leadership. New York: Harper and Row.

Caldwell, C., \& Anderson, V. (2020). University professors as “Transformative Leaders". The Journal of Values-Based Leadership, 14(1), Article 8. Retrieved from https://scholar.valpo.edu/jvbl/vol14/iss1/8

Caldwell, C., Dixon, R.D., Floyd, L.A., Chaudoin, J., Post, J., \& Cheokas, G. (2012). Transformative Leadership: Achieving unparalleled excellence. Journal of Business Ethics, 109, 175-187. DOI 10.1007/s10551-011-1116-2

Caldwell, C., McConkie, M., \& Licona, B. (2014). Simon Peter and Transformative Leadership: Leadership insights for today's leaders. Journal of Management and Strategy, 5(1), 18-32.

Carnegie Elective Classification for Engaged Institutions. (n.d.) Retrieved from https://www.brown.edu/academics/college/swearer/programs/college-and-university-engagementinitiative-cuei

Carnegie Elective Classification for Engaged Institutions Australian pilot. (2021). Retrieved from https://about.csu.edu.au/community/carnegie-community-engagement-classification 
Carnegie Elective Classification for Engaged Institutions Canadian pilot. (2021). Retrieved from https://www.sfu.ca/carnegie.html.

Carroll, B., \& Levy, L. (2010). Leadership development as identity construction. Management Communication Quarterly, 24(2), 211-231.

Charmaz, K. (2006). Constructing grounded theory: A practical guide through qualitative analysis. Sage.

Chase, S.E. (2005). Narrative inquiry: Multiple lenses, approaches, voices. In N.K. Denzin \& Y.S. Lincoln (Eds.), The Handbook of Qualitative Research (3rd ed., pp. 651-679). Thousand Oaks, Ca.: Sage.

Christie, M., Carey, M., Robertson, A., \& Grainger, P. (2015). Putting transformative learning theory into practice. Australian Journal of Adult Learning, 55(1), 9-30.

Croucher, G., \& Lacy, W.B. (2020). The emergence of academic capitalism and university neoliberalism: Perspectives of Australian higher education leadership. Higher Education: The International Journal of Higher Education Research. doi:10.1007/s10734-020-00655-7

Cunliffe, A.L. (2009). The philosopher leader: On relationalism, ethics and reflexivity-A critical perspective to teaching leadership. Management Learning, 40, 87-101.

Denscombe, M. (2014). The good research guide: For small-scale social research projects. McGraw-Hill Education (UK).

Ditto, P.H., \& Liu, B.S. (2016). Moral coherence and political conflict. In P. Valdesolo \& J. Graham (Eds.), Social Psychology of Political Polarization (pp. 102-122). Psychology Press.

Driscoll, A. (2014). Analysis of the Carnegie classification of community engagement: Patterns and impact on institutions. New Directions for Institutional Research, 162, 3-15.

Eagly, A.H. (2005). Achieving relational authenticity in leadership: Does gender matter? The Leadership Quarterly, 16(3), 459-474.

Engagement Academy for University Leaders. (n.d.). Retrieved from https:/engagementscholarship.org/conference/past-conferences/esc-2020-meeting/engagementacademy-for-university-leaders-virtual-seminar

Gilligan, C. (1993). In a different voice. Boston, MA: Harvard University Press.

Gilligan, C. (2011). Joining the resistance. Cambridge, UK: Polity Press.

Goleman, D. (1995). Emotional Intelligence: Why it can matter more than IQ. New York: Bantam Books.

Goodman M.S., Ackermann, N., Bowen, D.J., Panel, D., \& Thompson, V.S. (2020). Reaching consensus on principles of stakeholder engagement in research. Prog Community Health Partnerships, 14(1), 117-127. doi: 10.1353/cpr.2020.0014

Goodson, I.F., \& Gill, S.R. (2011). Narrative encounter: Human agency and social action. Counterpoints, 386, Narrative Pedagogy: Life History and Learning, pp. 93-112. Retrieved from https://www.jstor.org/stable/42981366

Hart, A., \& Northmore, S. (2011). Auditing and evaluating university-community engagement: Lessons from a UK case study. Higher Education Quarterly, 65(1), 34-58.

Hayibor, S., Agle, B., Sears, G., Sonnenfeld, J., \& Ward, A. (2011). Value congruence and charismatic leadership in CEO-top manager relationships: An empirical investigation. Journal of Business Ethics, 102(2), 237-254. http://dx.doi.org/10.1007/s10551-011-0808-y

Holland, B., \& Ramaley, J. (2008, July). Creating a supportive environment for community-university engagement: Conceptual frameworks. In HERDSA Annual Conference.

Horton, K.E., Saskia, P., Bayerl, P.S., \& Jacobs, G. (2014). Identity conflicts at work. Journal of Organizational Behavior, 35(1, Special Issue: The IRIOP Annual Review Issue), S6-S22.

Illeris, K. (2014). Transformative learning and identity. London, England: Routledge.

Kouzes, J.M., \& Posner, B.Z. (2010). The leadership challenge; How to keep getting extraordinary things done in organizations (4th ed.). San Francisco, CA: Pfeiffer.

Kurzwelly, J. (2019). Being German, Paraguayan and Germanino: Exploring the relation between social and personal identity. Identity, 19(2), 144-156. http://10.1080/15283488.2019.1604348

Larson, C.L., \& Murtadha, K. (2002). Leadership for social justice. Yearbook of the National Society for the Study of Education, 101(1), 134-161. 
Leggo, C. (2008). Narrative inquiry: Attending to the art of discourse. Language and Literacy, 10(1), $2-$ 21.

Malhotra, R., \& Kansa, R. (2017). Transformational leadership: An outcome of emotional intelligence. International Journal of Scientific Research and Education, 5(6), 6686-6691. http://dx.doi.org/10.18535/ijsre/v5i06.24

May, D.R., Chan, A.Y.L., Hodges, T.D., \& Avolio, B.J. (2003). Developing the moral component of authentic leadership. Organizational Dynamics, 32(3), 247-260. https://doi.org/10.1016/S00902616(03)00032-9

McCleskey, J. (2014). Emotional intelligence and leadership: A review of the progress, controversy, and criticism. International Journal of Organizational Analysis, 22(1), 76-93. https://doi.org/10.1108/IJOA-03-2012-0568

Mertova, P., \& Webster, L. (2012). Critical event narrative inquiry in higher education quality. Quality Approaches in Higher Education, 3(2), 15-21.

Mezirow, J. (2000). Learning to think like an adult: Core concepts of transformation theory. In J. Mezirow \& Associates (Eds.), Learning as transformation. Critical perspectives on a theory in progress (pp. 3-33). San Francisco: Jossey-Bass.

Mezirow, J. (2003). Transformative learning as discourse. Journal of Transformative Education, 1(1), 5863.

Mezirow, J. (2009). Transformative learning theory. In J. Mezirow, Taylor, E., \& Associates (Eds.), Transformative learning in practice. Insights from community, workplace, and higher education. San Francisco: Jossey-Bass.

Mills, J., Bonner, A., \& Francis, K. (2006). The development of constructivist grounded theory. International Journal of Qualitative Methods, 5(1), Article 3. Retrieved from $\mathrm{http}: / /$ www.ualberta.ca/ iiqm/backissues/5_1/pdf/mills.pdf

Morrison, E.A. (2020). Exploring community-engaged scholarship: Insights and questions for HRD. Advances in Developing Human Resources, 22(1), 41-56.

Ogunsanya, O., \& Govender, I. (2020). University-Community Engagement: Current tensions and future trends. International Journal of African Higher Education, 6(1), 51-76. https://doi.org/10.6017/ijahe.v6i1.11089

O’Meara, K. (2006). Encouraging multiple forms of scholarship in faculty reward systems: Influence on faculty work life. Planning for Higher Education, 34(2), 43-53.

O’Meara, K., \& Bloomgarden, A. (2010). The pursuit of prestige: Examining the consequences of striving for faculty work-life, reward systems, and satisfaction. Journal of the Professoriate, 4(1), 40-74.

Oxford Women's Leadership Program. (n.d.). Retrieved from https://onlineprogrammes.sbs.ox.ac.uk/presentations/lp/oxford-women-leadership-programme/

Ramaley, J.A. (2005, July). Engagement and the integration of research and education: A New meaning of quality. Keynote address to the Australian Universities Quality Forum.

Ricoeur, P. (1992). Oneself as another (K. Blamey, Trans.). Chicago7, University of Chicago Press.

Ruben, B.D., Di Lisi, R., \& Gigliotto, R.A. (2018). Academic leadership development programs: Conceptual foundations, structural and pedagogical components, and operational considerations. Journal of Leadership Education, 17(3), 241-254.

Saltmarsh, J., Janke, E.M., \& Clayton, P.H. (2015). Transforming higher education through and for democratic civic engagement: A model for change. Michigan Journal of Community Service Learning, 22(1), 122-127.

Sandmann, L.R., Thornton, C.H., \& Jaeger, A.J. (2009). The first wave of community-engaged institutions. In L.R. Sandmann, C.H. Thornton \& A.J. Jaeger (Eds.), Institutionalizing Community Engagement in Higher Education: The First Wave of Carnegie Classified Institutions (pp. 99104). New Directions for Higher Education, 147, Jossey-Bass.

Sermijn, J., Devlieger, P., \& Loots, G. (2008). The narrative construction of the self: Selfhood as rhizomatic story. Qualitative Inquiry, 14(4), 632-650. 
Singh, W. (2017). Gauging the impact of community university engagement initiatives in India. ASEAN Journal of Community Engagement, 1, 1-16.

Shields, C.M. (2004). Dialogic leadership for social justice: Overcoming pathologies of silence. Educational Administration Quarterly, 40, 111-134.

Shields, C. (2010). Transformative leadership: Working for equity in diverse contexts. Educational Administration Quarterly, 46(4), 558-589.

Shields, C.M. (2020). Transformative Leadership. Oxford Research Encyclopedias. Oxford, UK: Oxford University Press. Retrieved from

https://oxfordre.com/education/view/10.1093/acrefore/9780190264093.001.0001/acrefore9780190264093-e-632

Slaughter, S., \& Leslie, L.L. (1997). Academic Capitalism: Politics, Policies, and the Entrepreneurial University. Johns Hopkins University Press. Retrieved May 10, 2021, from https://search.ebscohost.com/login.aspx?direct=true \&db=cat03710a\&AN=alb.1970983\&site=eds -live\&scope $=$ site

Sparrowe, R.T. (2005). Authentic leadership and the narrative self. The Leadership Quarterly, 16, 419439.

Warhurst, R.P. (2012). Leadership development as identity formation: Middle managers' leadership learning from MBA study. Human Resource Development International, 15(4), 471-487.

Webster, L., \& Mertova, P. (2007). Using narrative inquiry as a research method: An introduction to using critical event narrative analysis in research on learning and teaching. London, UK, Routledge. 